\title{
MUJER E INMIGRACIÓN: EDUCACIÓN EN LAS AULAS.
}

Resumen. En este artículo recogemos lo que ha supuesto en la última década el proceso de la inmigración analizando las estadísticas del alumnado no universitario en el sistema educativo español. El objetivo principal es conocer las diferencias de género en función de la nacionalidad de $1 @$ s alumn@s y teniendo en cuenta los diversos niveles educativos. Para ello, se ha hecho un análisis completo de la estadística de alumn@s en el curso 2000-2001 y 2005-06, de los que hemos obtenido un mapa bastante matizado y completo de la presencia de niñas y jóvenes hijas de inmigrantes en el sistema escolar español.

Palabras claves: Inmigración, mujer inmigrante, género, educación, educación multicultural.

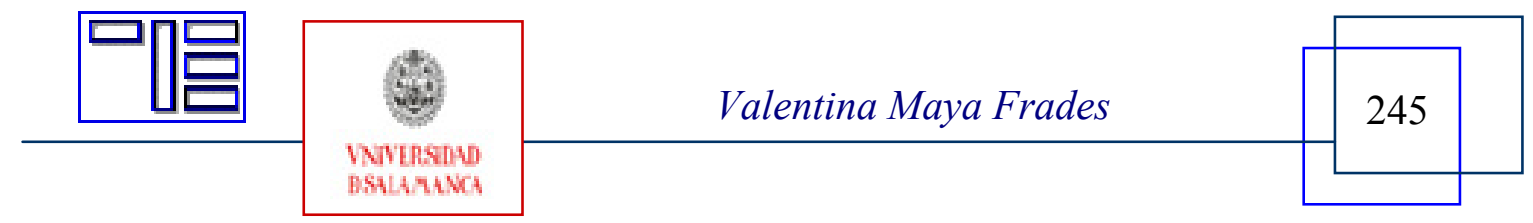


Revista Electrónica Teoría de la Educación.

Educación y Cultura en la Sociedad de la Información.

http://www.usal.es/teoriaeducacion

Vol. 9. No 2. Mayo 2008

\section{WOMAN AND INMIGRATION: EDUCATION IN THE CLASSROOMS.}

Abstract. In this article it is collected some assumptions from the past decade around the process of immigration, analyzing statistics of non-university students in the Spanish educational system. The main objective is to understand the gender differences depending on the nationality of students, taking into account the various levels of education. It has done a complete analysis of the statistics of student $\mathrm{s}$ in the course 2000-2001 and 2005-06, of which we have obtained a fairly nuanced and complete map of the presence of immigrants girls and young daughters in the Spanish school system.

Key words: Inmigration, immigrant women, gender, education, multicultural education.

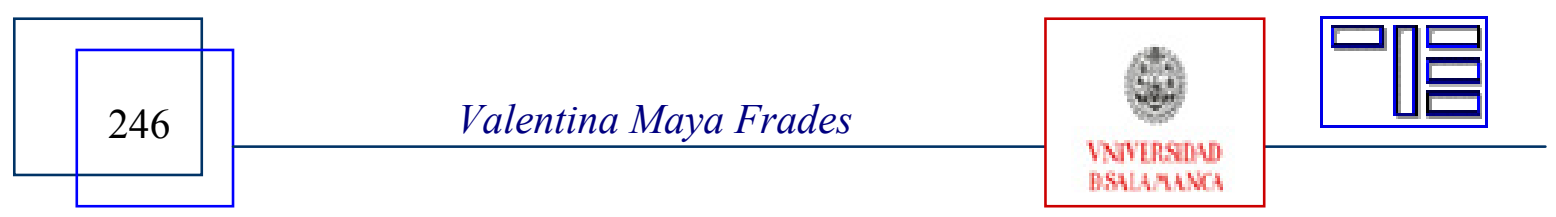




\section{FEMME ET INMIGRATION: EDUCATION DANS LES SALLES DE CLASSE.}

Sommaire. Dans cet article, nous recueillons ce qui a été produit dans la dernière décennie, le processus de l'analyse des statistiques de l'immigration non-étudiants universitaires dans le système éducatif espagnol. L'objectif principal est de comprendre les différences entre les sexes en fonction de la nationalité des personnes en tenant compte des différents niveaux d'enseignement. Y est présenté une analyse complète des statistiques de l'étudiant courant 2000-2001 et 2005-06, dont nous avons obtenu un résultat assez nuancé et une carte complète de la présence des filles et des jeunes filles d'immigrés dans le système scolaire espagnol.

Mots clés: Inmigration, femme immigrante, le genre, l'éducation, l'éducation multiculturelle.

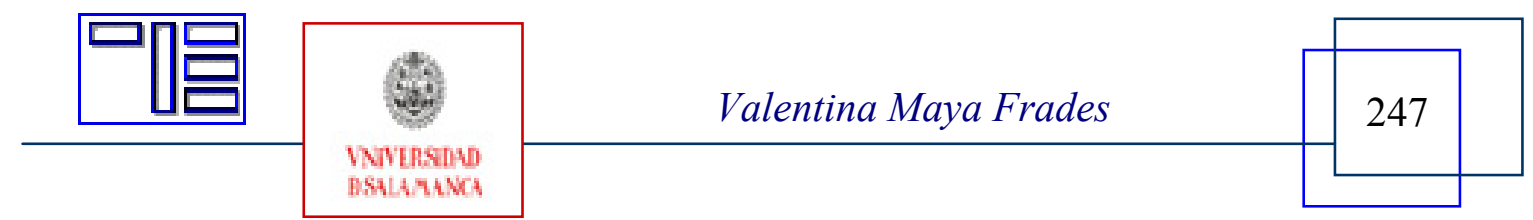


Revista Electrónica Teoría de la Educación.

Educación y Cultura en la Sociedad de la Información.

http://www.usal.es/teoriaeducacion

Vol. 9. No 2. Mayo 2008

MUJER E INMIGRACIÓN: EDUCACIÓN EN LAS AULAS.

Valentina Maya Frades

vmaya@usal.es

Universidad de Salamanca (España)

\section{1.- INTRODUCCIÓN.}

La emigración existe desde que los seres humanos habitamos el planeta, siempre ha sido esencial para el desarrollo de la humanidad y han estado involucradas personas de ambos sexos. Los pueblos han emigrado en busca de mejores condiciones de vida en la mayoría de los casos, el derecho a emigrar forma parte de la declaración universal de los Derechos Humanos ${ }^{1}$. La emigración por tanto, no sólo da vida al país de destino, sino que es todo un ciclo que se inicia desde la intención migratoria de individuos o grupos de individuos, que viven en una situación socio-económica determinada en el país de origen, hasta que llegan al país de acogida.

Las migraciones constituyen hoy un desafío y un reto en el siglo XXI, que no debe percibirse como una amenaza a la identidad española, sino más bien, como una ocasión de enriquecimiento mutuo, dentro de un mosaico pluricultural más democrático y plural. Aparte de que su presencia, incorporación al mundo del trabajo, el incremento del número de hijos de estas familias con el consiguiente aumento demográfico de población infantil, sin duda pueden aportar más beneficios que perjuicios. No obstante, hay que prevenir los posibles conflictos interétnicos, siendo el racismo y la xenofobia una de las amenazas perversas que pueden poner en peligro la construcción de una España más democrática y solidaria en la que todos- inmigrantes y autóctonos- deben participar y vivir en paz.

Los colectivos de inmigrantes no constituyen una población homogénea, sino que son muchos los elementos que confluyen en este hecho como son: antecedentes migratorios de la familia, círculo de amistades, sentimientos de insatisfacción, precariedad, expectativas de ascenso social, aspiraciones a derechos laborales, sociales, políticos o culturales, presión social, etc. Las migraciones son el resultado de la combinación cada vez más compleja de factores económicos (la expansión de las relaciones de producción de tipo capitalista, la generalización de la salarización, la proletarización masiva de las capas campesinas, la internalización de las economías), políticas (guerras, intereses estratégicos, hegemonía del modelo occidental...), sociales (pauperización, el desarraigo, la exclusión, la expropiación, la degradación medioambiental... (Ruíz, 2005)

Una de las consecuencias más visibles de este fenómeno migratorio ${ }^{2}$ es el inicio de un nuevo tipo de sociedades, que se caracterizan por la pérdida de homogeneidad, que incrementarán cada vez más su grado de multiculturalidad en el conjunto de las escalas

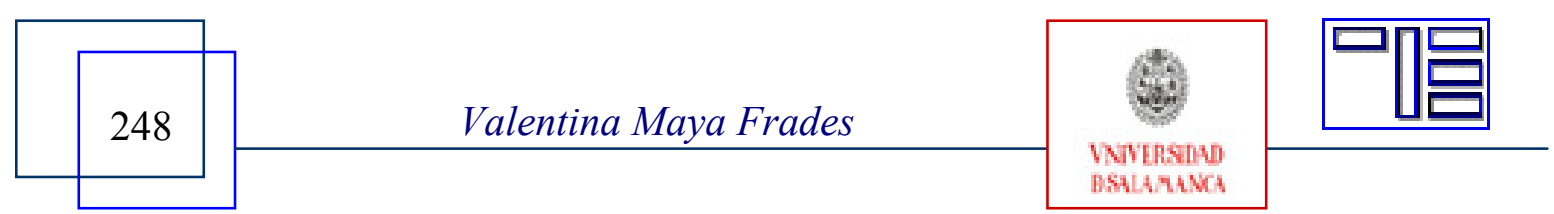


existentes entre lo local y lo mundial. Éstas se manifiestan ahora con un creciente grado de diversidad cultural. Poblaciones y grupos culturales diversos conviven en un mismo espacio, entran en contacto y en interacción, generando un nuevo tipo de sociedad. El encuentro y el diálogo con otras culturas son potencialmente enriquecedores para todas las partes implicadas, pero no es menos cierto que también son generadores de situaciones problemáticas y conflictivas. En definitiva, las sociedades se han hecho más complejas y deben encontrar los mecanismos y soluciones de todo tipo que den respuestas a esa complejidad.

En la sociedad española el fenómeno de acoger a una creciente cantidad de emigrantes es un hecho reciente ${ }^{3}$. Algunas consecuencias que han provocado tal fenómeno se están dando en el medio laboral, las relaciones humanas y sobre todo en el medio escolar. Las escuelas han ido acogiendo a niños y niñas inmigrantes de distintos países, lo que ha llevado a plantear algunas cuestiones, tales como:

- garantizarles una enseñanza digna y de calidad

- fomentar los valores de Interculturalidad y respeto en la comunidad educativa, es decir luchar contra el racismo y la xenofobia.

La sociedad española en pocos años ha pasado de ser una sociedad de emigrantes a otros países, a ser una sociedad de acogida, es decir, tenemos que convivir con muchas personas de otras latitudes del planeta como pueden ser personas venidas de África, América y el Este de Europa. Sin embargo, el fenómeno de la globalización en los años noventa ha llevado a aumentar las desigualdades socioeconómicas en el Tercer Mundo, viniendo crecientes oleadas de emigrantes al mundo occidental por problemas de hambre y por el señuelo de una vida mejor.

El objetivo planteado en este artículo es acercarnos al conocimiento del colectivo inmigrante femenino, así como llevar a cabo el análisis desde la vertiente sociológica de datos estadísticos segregados por sexo de dos cursos escolares, 2000-01 y 2005-06. La metodología que hemos utilizado para la elaboración de este artículo ha sido mediante la recopilación de fuentes secundarias a partir de las cuales elaboramos cuadros y gráficos con datos obtenidos de distinto origen: MEC, INE, Colectivo IOE.

La inmigración en la última década se está acelerando dentro del proceso de integración global. Las pautas migratorias que se están dando en todo el mundo pueden verse como un reflejo del rápido cambio que se está produciendo en los vínculos económicos, políticos y culturales que existen entre los países. La inmigración es el desplazamiento de personas a otro país para asentarse, y la emigración, el proceso por el cual la gente deja su país para asentarse en otro, se combinan para producir pautas migratorias globales que vinculan a los países de origen y a los receptores. Los movimientos migratorios aumentan la diversidad étnica y cultural de muchas sociedades y ayudan a configurar dinámicas demográficas, económicas y sociales.

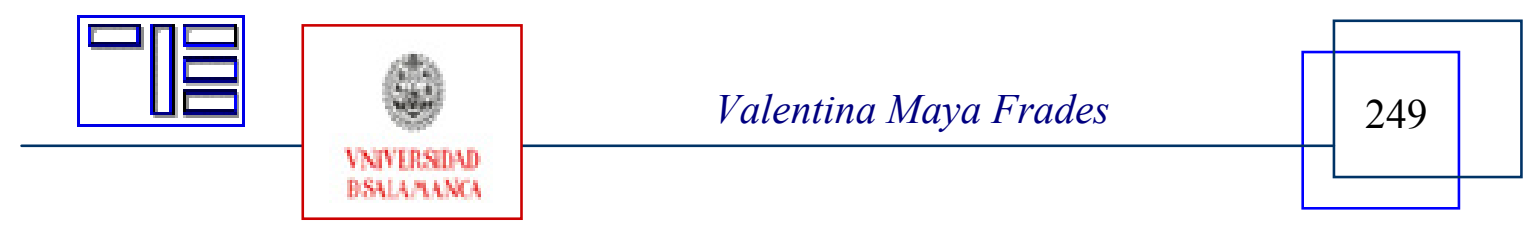


Revista Electrónica Teoría de la Educación.

Educación y Cultura en la Sociedad de la Información.

http://www.usal.es/teoriaeducacion

Vol. 9. No 2. Mayo 2008

El proceso migratorio se centra en una relación simétrica, porque hay unos factores que empujan y otros que tiran. Los que empujan son dinámicas que se producen dentro de cada país de origen que hace que las personas emigren, entre ellos la guerra, las hambrunas, la opresión política o las presiones demográficas. Por otra parte, los que tiran son aquellos que, dentro de los países receptores, atraen a los inmigrantes: por ejemplo, unos mercados laborales prósperos, unas mejores condiciones de vida y una menor densidad de población son factores que arrastran a los inmigrantes procedentes de otras zonas.

\section{2.- LA INMIGRACIÓN FEMENINA.}

Históricamente las mujeres han estado implicadas en las corrientes migratorias, aunque en la mayoría de los casos no aparezcan en las estadísticas, porque no se disponía de datos por sexo, inclusive las mujeres en muchas sociedades empiezan su primera inmigración cuando salen de la casa familiar, para formar parte del linaje del esposo (García Carrasco y otros, 2002). Los cambios habidos en la situación familiar, unidos a la movilidad y flexibilidad del mercado de trabajo han creado unas demandas laborales que son cubiertas en muchos casos por el sector femenino. Es ahora cuando vemos un gran aumento de las corrientes migratorias de carácter económico, utilizando mano de obra en los sectores reproductivos y en los trabajos de menor cualificación (Mujeres inmigrantes UGT, 2001).

Aunque a lo largo de la historia siempre ha habido presencia de las mujeres en las migraciones, ya señalaba Simone de Beauvoir, que en la mayoría de las culturas, las mujeres estaban acostumbradas a asumir "el papel del otro", a "empatizar", a adaptarse a las necesidades y a las circunstancias. Mientras que muchos hombres que llegan a los países de acogida viven este cambio como traumático, porque ven peligrar los privilegios, o el poder social del que gozaban en sus entornos de origen; las mujeres, hay que destacarlo, están más capacitadas para adaptarse a su nuevo hábitat y consecuentemente, si se les brinda la oportunidad de hacerlo, aprenderán con más facilidad que ellos las costumbres y formas de vida de los lugares de acogida. Esa mayor disposición de las mujeres a incorporarse a la cultura mayoritaria del país de destino no se hace, sin que experimenten un sentimiento de identidad dual: La cultura de procedencia y la nueva cultura con la que se encuentran (Martínez, 2003).

La perspectiva de género reconoce la influencia de las desigualdades entre los géneros que existen en los países, tanto de origen como de destino, e ilustra la forma en que esas desigualdades pueden afectar a las mujeres para el cambio, aunque al mismo tiempo pueden perjudicarlas en el proceso migratorio. La noción de género tiene su origen en las relaciones sociales y no puede ser considerada como algo fijo e inamovible a lo largo del tiempo y del espacio, y en este sentido difiere del término "sexo" que remite a los atributos biológicos de mujeres y hombres.

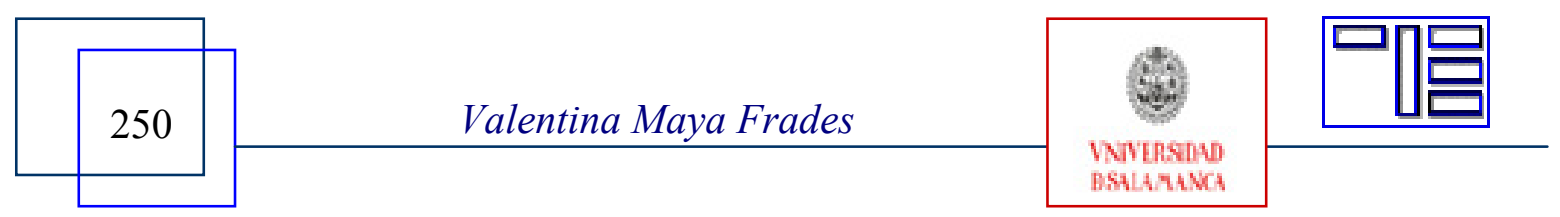


La desigualdad entre los géneros puede ser un poderoso factor que contribuye a precipitar la migración cuando las mujeres tienen expectativas económicas, políticas y sociales que las oportunidades disponibles en su país no satisfacen. La migración puede ser una experiencia potenciadora para la mujer. En el proceso de migración, las mujeres pueden dejar atrás situaciones de subordinación a la autoridad tradicional y patriarcal, y encontrarse en situaciones en que se sientan potenciadas para ejercer una mayor autonomía respecto de sus propias vidas. Las mujeres que se quedan atrás cuando sus maridos o hijos migran a menudo tienen que asumir nuevas funciones $\mathrm{y}$ responsabilidades en relación con las decisiones que afectan al bienestar social y económico de sus familias.

Las relaciones asimétricas de poder entre hombres y mujeres existen en razón de las normas y las prácticas de género imperantes. No obstante, las asimetrías también están arraigadas en las instituciones de la sociedad, que van desde la familia y el sistema educativo hasta los sistemas político y económico, así como jurídico. Están vinculadas a la desigualdad de acceso a los recursos, la condición social y económica disminuida, la vulnerabilidad al maltrato y la violencia, y a posibilidades limitadas en la vida. Las mujeres suelen estar en una posición de desventaja respecto a los hombres. Los factores relacionados con la sociedad incluyen las normas y los valores culturales de la comunidad, que determinan si las mujeres pueden migrar o no y, en caso afirmativo, en qué condiciones (por ejemplo, por trabajo o por reunificación de la familia ${ }^{4}$ y con quién (sola o con la familia)" (Boyd \& Grieco, 2003, 3).

En el periodo 2001-2006 (cuadro1) se refleja el aumento de la población extranjera en relación al aumento que ha experimentado la población española, es decir, se pretende medir el efecto de la población extranjera en la variación total de la población. Se entiende por población extranjera la que está empadronada y no tiene la nacionalidad española. En España los extranjeros han contribuido a la variación de la población total con 2.773.517 habitantes, y los españoles con 817.029 habitantes. En relación a la diferenciación que se produce en el sexo es clara como vemos en el cuadro, en los extranjeros en los dos años el porcentaje de hombres es mayor que el de las mujeres, sin embargo, vemos como se produce un aumento de una décima en el año 2006 en las mujeres. En los españoles se produce el fenómeno inverso, el porcentaje de mujeres es mayor en los dos años que el de los hombres.

Cuadro 1: Población extranjera y española según sexo. 2001-2006

\begin{tabular}{|c|c|c|c|c|c|c|c|}
\hline \multicolumn{4}{|c|}{ EXTRANJEROS } & \multicolumn{4}{|c|}{ ESPAÑOLES } \\
\hline & & & & & & & \\
\hline $\begin{array}{c}\text { Hombres } \\
55 \%\end{array}$ & $\begin{array}{c}\text { Mujeres } \\
45 \%\end{array}$ & $\begin{array}{c}\text { Hombres } \\
54 \%\end{array}$ & $\begin{array}{c}\text { Mujeres } \\
46 \%\end{array}$ & $\begin{array}{c}\text { Hombres } \\
49 \%\end{array}$ & $\begin{array}{c}\text { Mujeres } \\
51 \%\end{array}$ & $\begin{array}{c}\text { Hombres } \\
49,4 \%\end{array}$ & $\begin{array}{c}\text { Mujeres } \\
50,6 \%\end{array}$ \\
\hline
\end{tabular}

Fuente INE. Elaboración propia

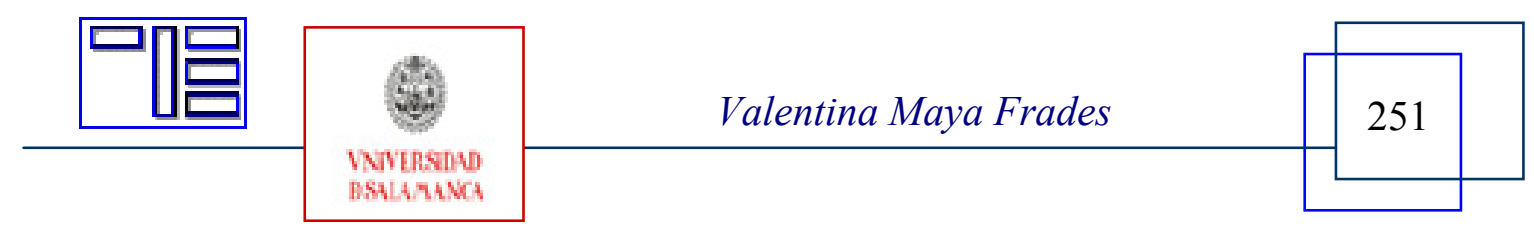


Revista Electrónica Teoría de la Educación.

Educación y Cultura en la Sociedad de la Información.

http://www.usal.es/teoriaeducacion

Vol. 9. No 2. Mayo 2008

Los ciudadanos extranjeros que viven en España en el 2007 son 3.979.014, con certificado de registro o tarjeta de residencia en vigor; representan el 8,8 por ciento de la población española fijada en 45.200 .737 habitantes $^{5}$, el 45,6 por ciento son mujeres y el 54,4 por ciento varones. (http://extranjeros.mtas.es). El mayor porcentaje $(38,9 \%)$ de extranjeros que han venido a nuestro país en la fecha anteriormente señalada proceden de la Europa Comunitaria, el 30,6 por ciento es iberoamericano, el 21,2 por ciento africano, el 6 por ciento asiático, el 2,9 por ciento es europeo de países no comunitarios, el 0,5 por ciento norteamericano y el 0,1 por ciento de países de Oceanía. De 1.130 personas no consta la nacionalidad o figuran como apátridas. La comunidad extranjera más numerosa sigue siendo la marroquí, con 648.735 personas (16 por ciento del total de foráneos), seguida de la rumana con 603.889, y la ecuatoriana, con 395.808 (15 y 10 por ciento respectivamente); le siguen el colectivo colombiano, británico, búlgaro, italiano...

En el gráfico 1 podemos observar el porcentaje de extranjeros que tienen la tarjeta de residencia, así mismo vemos que en todas las comunidades el porcentaje de mujeres es menor que el de los hombres, sin embargo, es en las Comunidades de Murcia, Extremadura, Aragón, Castilla La Mancha y La Rioja en donde la desigualdad entre sexos es mayor la diferencia. Así mismo podemos observar que en las Comunidades de Galicia y Ceuta el porcentaje de extranjeros según el sexo es prácticamente igual entre ambos.

\section{Gráfico 1: Extranjeros con tarjeta de residencia según comunidad y sexo}

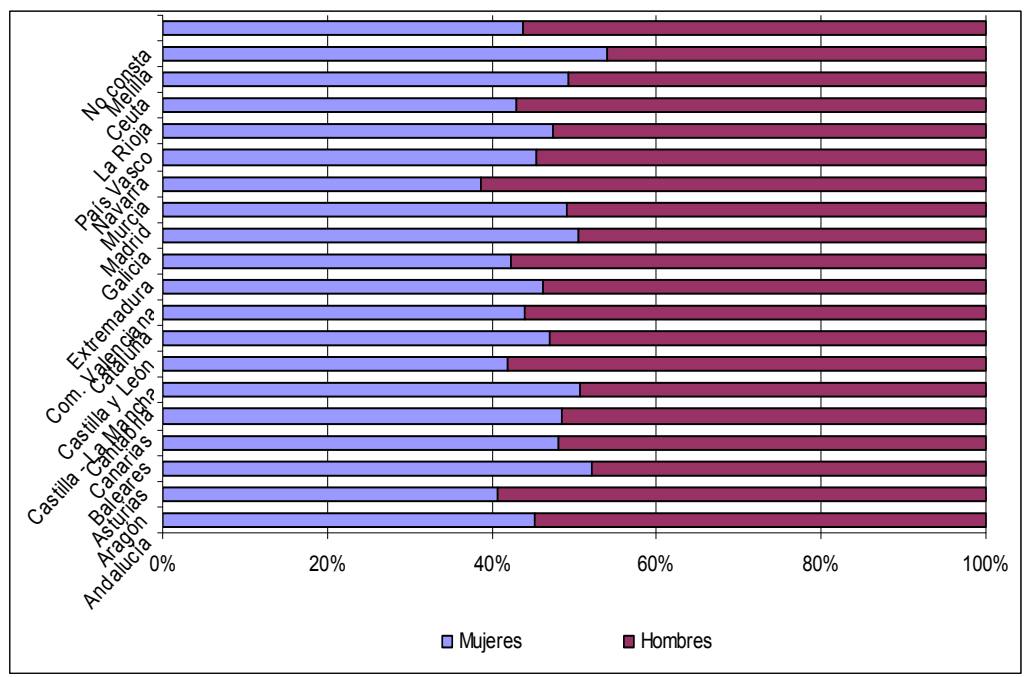

Fuente INE. Elaboración propia

Cada vez son más numerosas las mujeres inmigrantes. Se trata incluso ya de un fenómeno que tiene su propia entidad. La condición de mujer inmigrante, como fenómeno autónomo, depende del país de origen de que se trate. Mientras las mujeres de

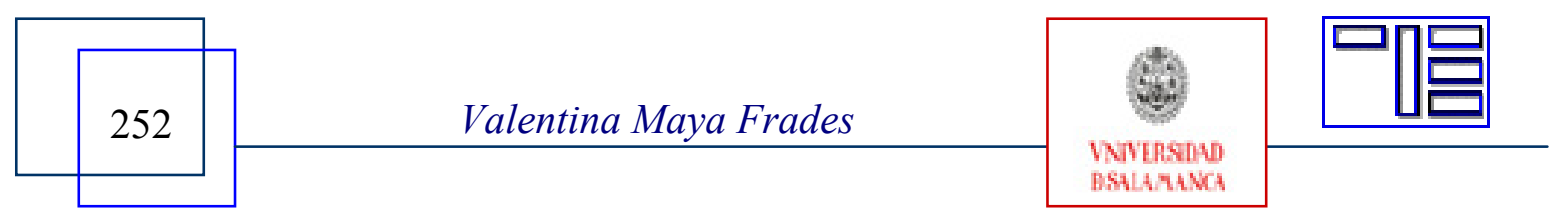


la Unión Europea son en algunos países superiores en número al de los hombres (Alemania, Austria, Bélgica, Dinamarca, Finlandia, Francia y Suecia), sin embargo, todavía son más los países en los que el número de hombres que han emigrado son mayores que el de las mujeres, lo que nos hace pensar que aún queda mucho que hacer para que la igualdad entre mujeres y hombres se alcance. Entre las latinoamericanas tales cifras alcanzan mayores proporciones ( 2 de cada 3 personas inmigrantes de América Central son mujeres, el 69 por ciento dominicanas, el 58 por ciento colombianas, aunque también hay otros países en los que el número de mujeres es mayor, como México, Ecuador, etc.). No ocurre lo mismo con la mayor parte de las inmigrantes africanas del área subsahariana o del Magreb. Sin embargo, no hay que olvidar que cada vez son más las mujeres que cruzan solas el estrecho en pateras, incluso en condiciones personales especialmente penosas, algo que, hasta hace muy poco tiempo, resultaba impensable.

El aumento de las mujeres que emigran es que muchas de ellas están llegando a los países receptores, no como parte de su entidad familiar, sino como personas con plena autonomía, dejando al marido e hijos e hijas en el país de origen hasta ser ellas la pieza fundamental de la subsistencia común. Las mujeres, en estos casos, son las que envían recursos a los suyos, a la espera de un reagrupamiento familiar ${ }^{6}$, o son el elemento fundamental para la compra de la vivienda, para el establecimiento de un negocio o para el sostenimiento familiar. En algunos estudios ya se ha dicho que las mujeres inmigrantes son un conjunto poco visible muchas veces, sobre todo en el caso de mujeres en situación de irregularidad, que se dedican a trabajos o tareas de fácil ocultación y casi siempre relacionadas a funciones domésticas o al cuidados de menores y personas ancianas.

Gráfico 2: Extranjeros según grupos de edad y sexo. 2001

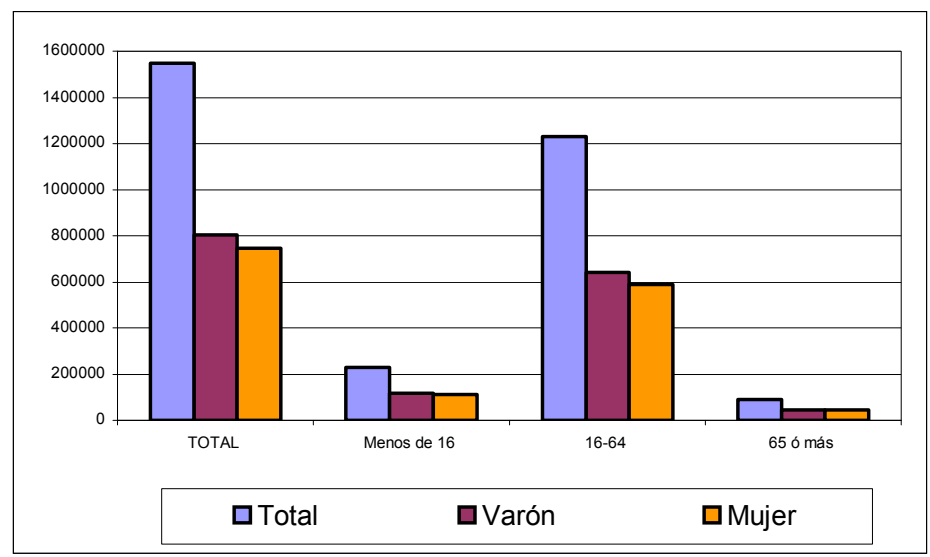

Fuente INE. Elaboración propia

La estructura de la población inmigrante tal y como vemos en el gráfico 2 el mayor número de inmigrantes está en la cohorte de edad comprendida entre 16-64 años, algo

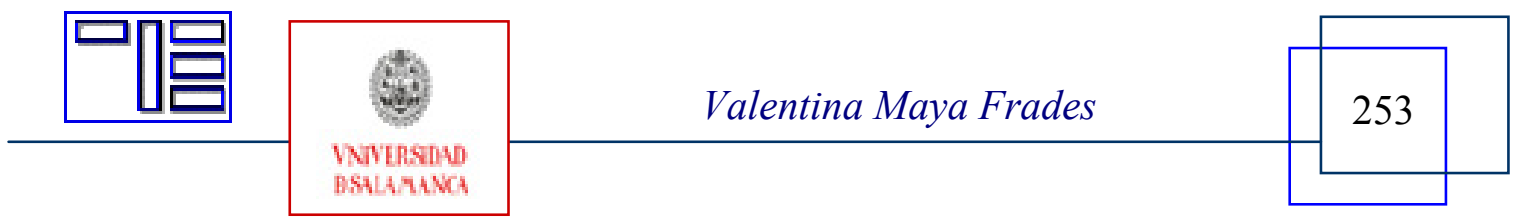


Revista Electrónica Teoría de la Educación.

Educación y Cultura en la Sociedad de la Información.

http://www.usal.es/teoriaeducacion

Vol. 9. No 2. Mayo 2008

lógico, puesto que es la edad de donde se nutre el mercado laboral y si han emigrado de su país es buscando un trabajo para poder mejorar su nivel de vida y ayudar a su familia, la diferencia de género es mínima, aunque es algo más que la que podemos observar entre los menores de 16 años que son prácticamente iguales.

\section{3.- LA EDUCACIÓN MULTICULTURAL.}

La presencia creciente de inmigrantes extranjeros en España no se limita sólo a las personas adultas: una parte importante de los recién llegados son menores de edad. Además, de las migraciones familiares y de la constitución de nuevas parejas, en la emigración deriva el nacimiento -en suelo español- de hijos de extranjeros, muchos de los cuales conservan la ciudadanía originaria de sus padres. Estas generaciones jóvenes, procedentes directa o indirectamente de la inmigración, constituyen poblaciones nuevas que han de insertarse en las instituciones del país de residencia, entre las cuales hay que destacar el sistema escolar.

El proceso de escolarización es uno de los elementos clave a la hora de configurar las modalidades de socialización e inserción social de estas nuevas generaciones. En las aulas, los hijos de inmigrantes pueden acceder -con más facilidad que su padres- al aprendizaje de los códigos básicos de la sociedad española (incluidas las lenguas autóctonas) e iniciar un proceso de cualificación formalizado. En la medida en que el sistema escolar es el encargado de inculcar los valores básicos que definen la sociedad de acogida, según el estándar dominante, es un vehículo de reproducción social que pone el énfasis en los valores autóctonos. Por otra parte, la creciente diversidad del alumnado y los recientes desarrollos legislativos tienden a prestar más atención a la convivencia intercultural, y a tomar en cuenta las realidades sociales específicas del alumnado. De esta manera, el sistema escolar español se mueve entre la inercia de reproducir lo existente y la apertura -incipiente y con muchas dificultades- hacia las aportaciones de un alumnado social y culturalmente diverso.

La Asamblea General de las Naciones Unidas, en el artículo 26 dice que: Toda persona tiene derecho a la educación. La educación debe ser gratuita, al menos en lo concerniente a la instrucción elemental y fundamental. La instrucción elemental será obligatoria. La instrucción técnica y profesional habrá de ser generalizada; el acceso a los estudios superiores será igual para todos, en función de los méritos respectivos. Los padres tendrán derecho preferente a escoger el tipo de educación que habrá de darse a sus hijos.

Junto al currículum oficial del sistema escolar existe un currículum oculto del que forman parte importante las pautas no explícitas, y a veces no conscientes, que el profesorado transmite en sus interacciones cotidianas:

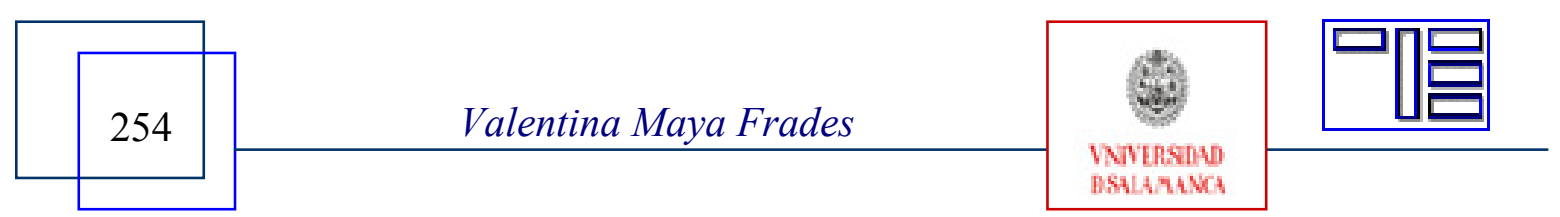


"El sistema educativo no sólo transmite y evalúa el aprendizaje del currículum oficial, sino que también transmite, a través de la interacción de docentes y alumnos, un conjunto de normas y pautas de comportamiento y de relación muy importantes en la modelación de actitudes posteriores que configuran un aprendizaje paralelo (...) una serie de nociones y pautas no explícitas que influyen decisivamente sobre la autovaloración de niños y niñas en las opciones y actitudes que van tomando a lo largo de su educación y en los resultados finales: es lo que se ha denominado el currículum oculto". (Subirats, 1994, p. 68)

Dentro de la política educativa de equidad es importante conocer la situación de determinados colectivos que, en principio, pueden presentar desventajas al incorporarse al sistema educativo español, para así poder planificar posteriormente los recursos que compensen las desigualdades iniciales. En esta situación de desventaja inicial se puede considerar al alumnado extranjero, dadas sus diferencias culturales y lingüísticas, con el resto de alumnos escolarizados. La nota más distintiva es, sin embargo, el rápido crecimiento de esa población escolar. En los últimos cursos, el número de alumnos extranjeros en edad escolar se ha cuadruplicado, de tal forma que ésta es la causa que explica el pequeño aumento del alumnado total registrado en algunas Comunidades de España, cuya dinámica demográfica general tiende más bien a la baja. El ritmo de incremento anual se sitúa en torno al 50 por ciento y se prevé que siga acelerándose en el futuro.

La educación multicultural $^{7} \mathrm{y}$, por consiguiente, su práctica educativa ha sido con excesiva frecuencia confusa, contradictoria e incoherente, de ahí que cuando se habla de enseñar cualquier disciplina en un aula multicultural, ésta ha estado ligada a la visión que los profesores han tenido sobre la enseñanza, en general, y de su concepción de la sociedad, en particular. Es necesario conseguir que los profesores tomen conciencia de que el aula refleja la sociedad actual y representa a sí mismo lo que es un hecho, la diversidad cultural ${ }^{8}$, identificada a partir de parámetros como la etnia, el género, la orientación sexual, la edad, entre otros factores, significa por tanto, asumir la idea de que la transformación cultural corre paralela a la transformación de la escuela y, por tanto, al cambio educativo y docente (Bajo \& Maya, 2007).

La educación juega un papel importante para dar respuesta a la diversidad cultural. Las administraciones educativas pueden ofrecer la educación obligatoria a todo el alumnado, aunque con opciones diferenciadas, siempre en función del modelo social que pretendan. Los alumnos pueden matricularse en diferentes centros según las características de los alumnos: centros de educación especial, centros para extranjeros de la misma lengua...sería la oferta educativa, pero con un modelo segregado, que conduce a una sociedad organizada en compartimentos estancos. En el polo opuesto estaría el modelo integrador, que escolariza a todos los niños en los mismos centros, organizando las ofertas para dar respuestas adecuadas a sus diferencias de partida, aunque pretendiendo unas mismas metas de llegada. Luego este es el camino a seguir si somos diferentes y tenemos que vivir juntos debemos educarnos juntos. Los niños no

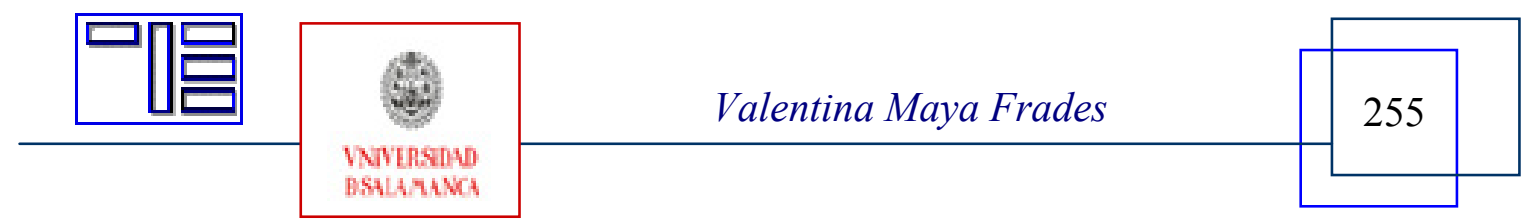


Revista Electrónica Teoría de la Educación.

Educación y Cultura en la Sociedad de la Información.

http://www.usal.es/teoriaeducacion

Vol. 9. No 2. Mayo 2008

plantean prejuicios en su trato con los compañeros si no se lo inculcamos los adultos (familia-profesor) y comienzan a reproducir las actitudes que ven en casa o en determinadas escuelas. Además de este modelo educativo que favorece la diversidad del alumnado, hay que incorporar la educación intercultural, para todos, con planteamientos transversales que afecten al conjunto del desarrollo curricular y organizativo del mismo (Soriano, 2005, p. 30).

Por consiguiente, la educación multicultural no puede alcanzarse añadiendo simplemente algunas informaciones a los currícula actuales. El cambio tendría que ser global y afectar a distintos niveles, llevando consigo revisiones de aspectos tan diversos como las políticas educativas, la organización del currículum, los textos y los materiales de estudio, la evaluación, etc., todo ello debería proyectarse en una formación del profesorado adecuada a este cambio cultural y a su desarrollo profesional.

La integración de los inmigrantes debe abordarse desde una perspectiva integral y no sectorial; sólo desde enfoques sistémicos pueden encararse fenómenos complejos que se caracterizan por la interrelación y la interdependencia. En una entrevista a un alumno universitario nos respondía así cuando le preguntábamos sobre la integración:

¿Dirías entonces que tus compañeros de clase no te aceptaban? No es eso, sí que me aceptaban, pero como algo distinto. Lo que yo no entendía era por qué era yo el distinto y no otro. Es cierto que yo venía de fuera, pero también había gente distinta por otros motivos y eso no se tenía tan en cuenta. Esto no pasaba sólo con los compañeros, sino también los profesores. Por ejemplo, cuando estaba en Primaria llegó una chica venezolana a nuestra clase. La profesora automáticamente me puso con ella, a que le enseñara cómo eran las cosas aquí. Lo que esta mujer no parecía entender es que Argentina y Venezuela tienen poco que ver y que yo de aquella era más español que otra cosa. Pero ellos sólo veían que uno era extranjero, no hacían diferencia más allá de eso. Es lo de antes, lo aceptan (quizás porque no les queda alternativa) pero no acaban de entender que a menudo eran muchas más las cosas que nos unían, a los inmigrantes y a los españoles, que las que nos diferenciaban (alumno inmigrante argentino).

\section{4.- EL ALUMNADO EXTRANJERO.}

Hace algunos años, el hecho de que hubiera una persona extranjera en un aula era algo novedoso y chocante para los alumnos. Sin embargo, algunos profesores aprovechaban la situación para incluir en sus clases otras perspectivas o experiencias de vida. Los niños y las niñas, ante estos casos aislados de personas extranjeras, sienten curiosidad y desarrollan, por lo general, una actitud positiva de integración. Actualmente la situación ha cambiado, la inmigración se ha masificado y nos encontramos que en nuestras aulas hay niños y niñas, búlgaros, rumanos, bosnios, ucranianos o magrebíes, cada uno, cada una con un pasado, una historia escolar y una historia familiar no siempre placentera,

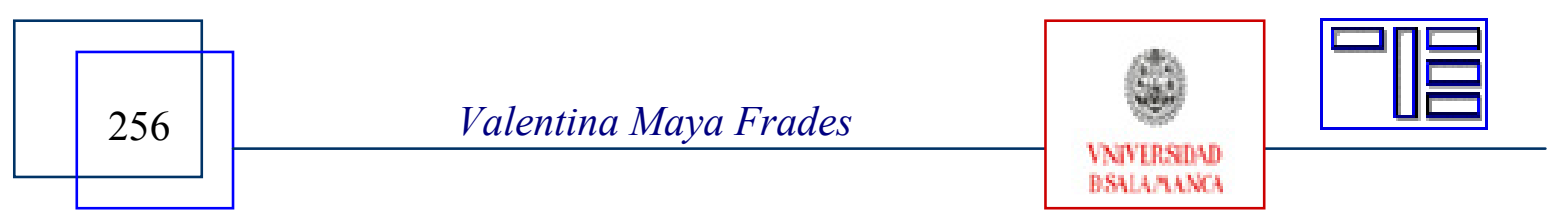


han salido de sus países de origen por razones variadas, por las que las personas cambian de lugar, pobreza, persecución, intolerancia, pero todos y todas llegan con una esperanza común: vivir en un mundo mejor y poder tener un futuro para sus hijas e hijos, y aquí están queriendo prepararse para ese futuro más esperanzador. Nuestra escuela, nuestra clase es el primer peldaño a ese camino de esperanza.

En la mayoría de los casos sucede que los desconocemos, no entendemos sus reacciones, porque no sabemos nada de su sufrimiento ni de sus desventuras, no podemos comunicarnos con ellos porque no saben nuestro idioma y pedimos apoyos, alguien de compensatoria, alguien de lengua, que los pongan en las clases de los alumnos más pequeños, alguien de... en algunas ocasiones se nos olvida que no padecen deficiencia alguna, solamente desconocen el idioma y la cultura, están enfadados y no les gusta lo que han encontrado aquí.

El alumnado extranjero ${ }^{9}$ en España en la última década ha experimentado un aumento espectacular en todas las comunidades autónomas, así podemos ver en el cuadro 2 que desde el curso 2000-01 hasta el 2005-06 ha crecido en 38.651 personas más. Si analizamos estos dos cursos, en ellos aparecen las mismas Comunidades cuyo número de alumnos/as extranjeros/as ha aumentado más, estas son: Madrid, Cataluña y Andalucía. Mientras que en el curso 2005-06 las provincias que más alumnos extranjeros tienen son: Almería, Málaga, Zaragoza, Toledo, Barcelona, Alicante, Burgos, Valladolid...

El alumnado extranjero son los alumnos que no poseen la nacionalidad española y que su procedencia es diversa. La presencia de este grupo es relativamente reciente en los centros escolares españoles, pero está adquiriendo una particular relevancia en los últimos años, lo que ha obligado a las Administraciones y a las comunidades educativas a reformular principios de actuación.

Existe una franja significativa de la población femenina de origen extranjero que está en edad escolar. Según el Censo del 2001 las niñas que cursan los estudios obligatorios (educación infantil, primaria, especial y E.S.O) representaban el 84,9 por ciento del alumnado femenino extranjero, mientras que en el año 2006 se ha producido un aumento de 2,3 décimas, lo que justifica el aumento de la población inmigrante, no solamente los/as cabezas de familia sino que se produce una inmigración de familias enteras a nuestro país.

Cuadro 2: Alumnado extranjero matriculado por comunidad autónoma.

\begin{tabular}{|llll|}
\hline & $2000-01$ & & $2005-06$ \\
Mujeres & Hombres & \\
Andalucía & 10.353 & 11.214 & 60.218 \\
Aragón & 2695 & 2804 & 16.558 \\
Asturias & 754 & 767 & 4.073 \\
Baleares & 4.400 & 4.613 & 19.161 \\
Canarias & 5.738 & 6.159 & 26.759 \\
\hline
\end{tabular}

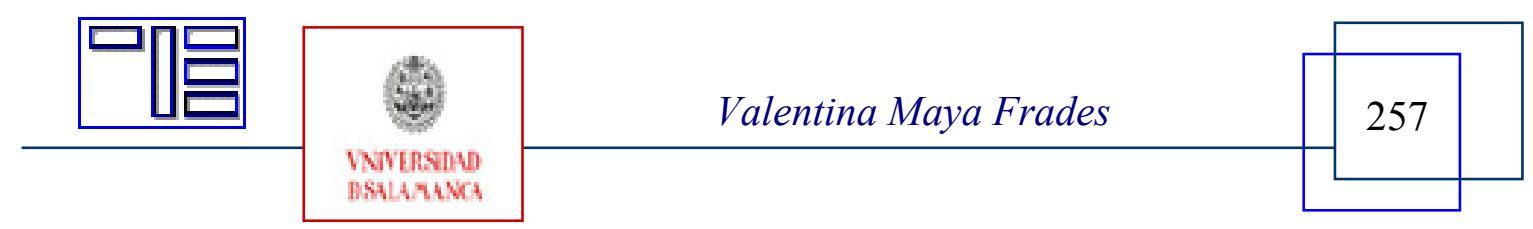


Revista Electrónica Teoría de la Educación.

Educación y Cultura en la Sociedad de la Información.

http://www.usal.es/teoriaeducacion

Vol. 9. No 2. Mayo 2008

\begin{tabular}{|llll|}
\hline Cantabria & 521 & 495 & 3.662 \\
Castilla - La Mancha & 2.650 & 2.740 & 19.476 \\
Castilla y León & 2.913 & 3.015 & 17.690 \\
Cataluña & 24.496 & 25.820 & 110.388 \\
Com. Valenciana & 11.495 & 12.182 & 70.754 \\
Extremadura & 866 & 1.004 & 4.018 \\
Galicia & 2.271 & 2.357 & 8.921 \\
Madrid & 26.149 & 27.263 & 114.566 \\
Murcia & 4.399 & 4.489 & 25.773 \\
Navarra & 1.679 & 1.741 & 8.640 \\
País Vasco & 1.947 & 1.971 & 12.745 \\
La Rioja & 933 & 944 & 4.930 \\
Ceuta & 155 & 150 & 251 \\
Melilla & 596 & 618 & 878 \\
Total & 105.010 & 110.346 & 529.461 \\
\hline
\end{tabular}

Fuente: INE. Elaboración propia

En este artículo queremos ofrecer la información existente respecto a la escolarización de esta población. Para ello hemos de hacer uso de cifras oficiales pero poco conocidas. De hecho, hasta la fecha las publicaciones oficiales de datos del alumnado extranjero no incluyen la segregación por sexo. La información que utilizamos en este artículo es la ofrecida por el INE, MEC y MTAS en el curso 2000-2001 y 2005-06.

Las principales características que hemos extraído del análisis de los datos de estos dos cursos son las siguientes:

- La primera observación llevada a cabo en los cursos comprendidos entre 20002001 y 2005-2006 es el volumen de alumnas extranjeras en España que se ha multiplicado 3,8 veces, pasando de 69.264 a 262.604. Puede decirse, por tanto, que el fuerte crecimiento de la inmigración extranjera en los últimos años se refleja también en las aulas españolas.

- En segundo lugar, la distribución de este alumnado entre los distintos niveles educativos $^{10}$, muestra un predominio de la educación Primaria (gráfico $3 \mathrm{y}$ cuadro 3), que acoge al 41 por ciento de las extranjeras escolarizadas en España, aumentando en una décima en el curso 2005-06. Le siguen las alumnas extranjeras matriculadas en la E.S.O. (26\%) y en la enseñanza Infantil (17\%), no habiendo apenas diferencias entre los dos cursos. Por tanto, estos tres niveles, que comprenden los tramos de enseñanza obligatoria en España, reúnen al 84 por ciento de las menores de origen inmigrante. El 16 por ciento restante se distribuye en los otros niveles. Sin embargo, sí tenemos que resaltar que en el curso 2005-06 las alumnas matriculadas es menor en idiomas, mientras que en Formación Profesional aumenta en un punto y medio (gráfico 4). Estos datos que hemos analizado muestran que la llegada de niñas inmigrantes a los centros escolares españoles, en los años recientes, se ha producido especialmente en el tramo inferior de la enseñanza obligatoria (etapa Infantil), mientras que en la

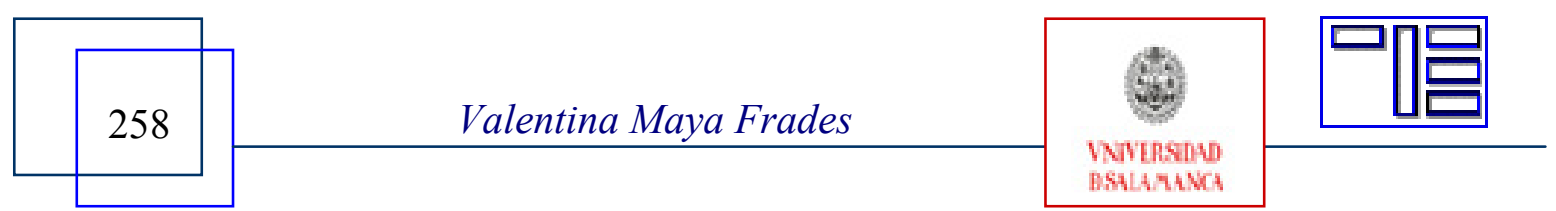


etapa no obligatoria ha crecido más la matrícula en la Formación Profesional que en Bachillerato. Las cifras del conjunto del alumnado femenino muestran que la proporción de mujeres es mayor que la de los hombres en los niveles no obligatorios (bachillerato y formación profesional). Esta circunstancia parece indicar que -en general- las chicas continúan estudiando en mayor proporción que los varones. Esta circunstancia se verifica especialmente entre el alumnado procedente de América, África y Europa (cuadro 3).

\section{Gráfico 3: Alumnado extranjero por nivel educativo y sexo. Curso 2000-01}

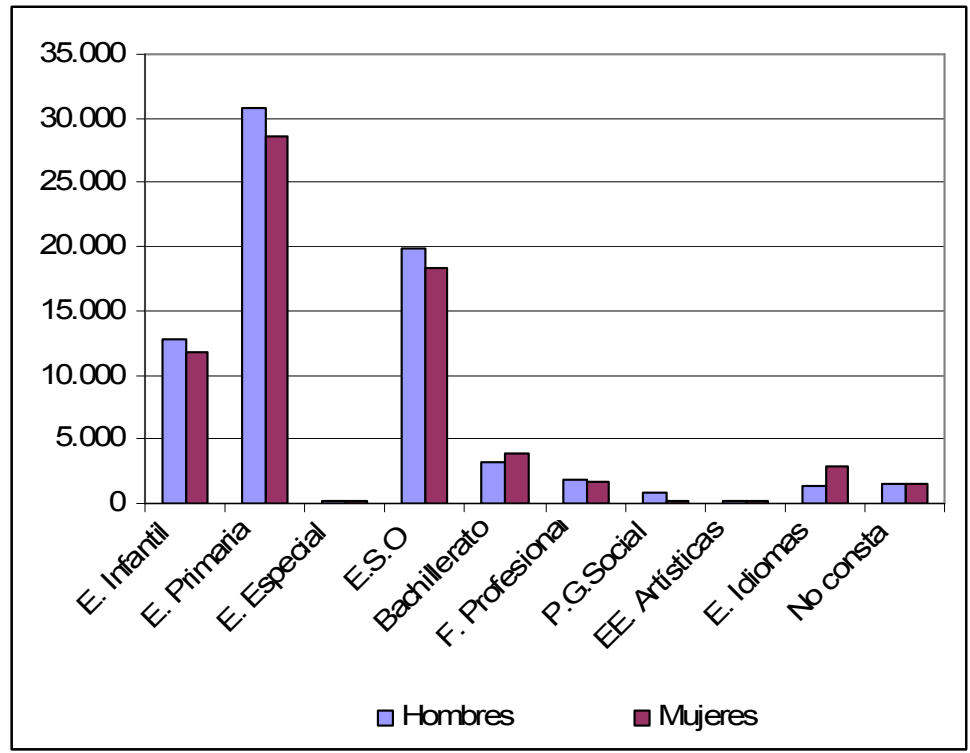

Elaboración propia a partir de datos del MEC

Cuadro 3: Alumnado extranjero por país de nacionalidad, sexo y nivel educativo. Curso 2000-01

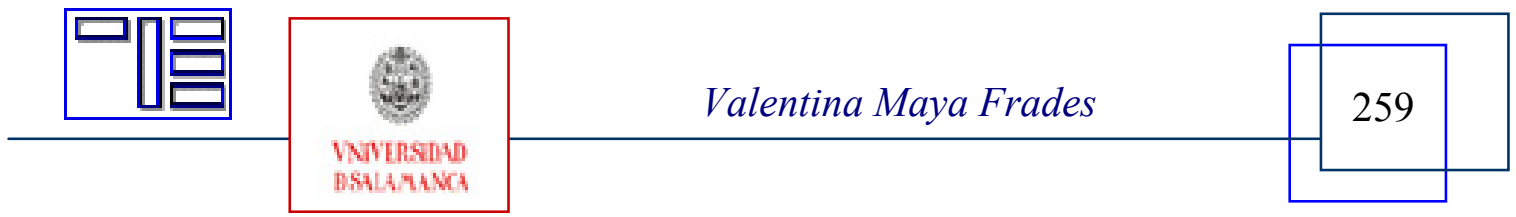


Revista Electrónica Teoría de la Educación.

Educación y Cultura en la Sociedad de la Información.

http://www.usal.es/teoriaeducacion

Vol. 9. No 2. Mayo 2008

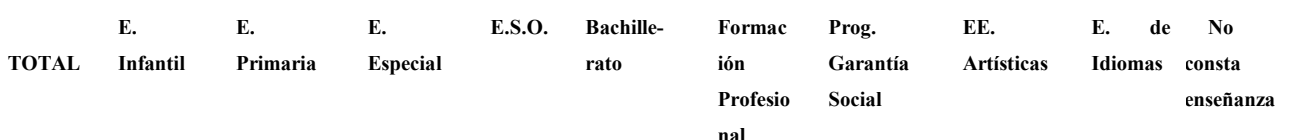

\begin{tabular}{|c|c|c|c|c|c|c|c|c|c|c|c|c|}
\hline \multirow[b]{2}{*}{ Total } & & & & \multicolumn{9}{|c|}{ nal } \\
\hline & Hombres & 72.604 & 12.760 & 30.858 & 246 & 19.851 & 3.170 & 1.856 & 758 & 136 & 1.420 & 1.549 \\
\hline Europa & Hombres & 15.249 & 2.435 & 6.263 & 26 & 3.411 & 918 & 372 & 53 & 38 & 455 & 1.278 \\
\hline Resto de & Hombres & 6.144 & 1.057 & 2.656 & 9 & 1.624 & 330 & 163 & 33 & 18 & 123 & 131 \\
\hline Europa & Mujeres & 6.283 & 964 & 2.500 & 14 & 1.610 & 402 & 130 & 8 & 32 & 494 & 129 \\
\hline África & Hombres & 21.405 & 4.209 & 9.112 & 113 & 6.370 & 359 & 570 & 465 & 7 & 177 & 23 \\
\hline América & Hombres & 1.495 & 238 & 592 & 3 & 349 & 177 & 35 & 2 & 11 & 48 & 40 \\
\hline del Norte & Mujeres & 1.329 & 200 & 527 & 4 & 289 & 170 & 27 & 1 & 11 & 69 & 31 \\
\hline América & Hombres & 4.231 & 560 & 1.849 & 26 & 1.480 & 149 & 79 & 60 & 7 & 21 & 0 \\
\hline Central & Mujeres & 4.560 & 528 & 1.856 & 18 & 1.656 & 243 & 151 & 39 & 12 & 57 & 0 \\
\hline América & Hombres & 18.681 & 3.356 & 8.213 & 59 & 5.097 & 941 & 573 & 133 & 31 & 262 & 16 \\
\hline & Mujeres & 72 & 14 & 22 & 0 & 11 & 10 & 3 & 0 & 0 & 11 & 1 \\
\hline No consta & Hombres & 58 & 4 & 13 & 0 & 11 & 6 & 0 & 1 & 0 & 1 & 22 \\
\hline país & Mujeres & 86 & 8 & 21 & 0 & 11 & 1 & 0 & 0 & 0 & 8 & 37 \\
\hline
\end{tabular}

Fuente: MEC. Elaboración propia

Gráfico 4: Alumnado extranjero por nivel educativo y sexo. Curso 2005-06

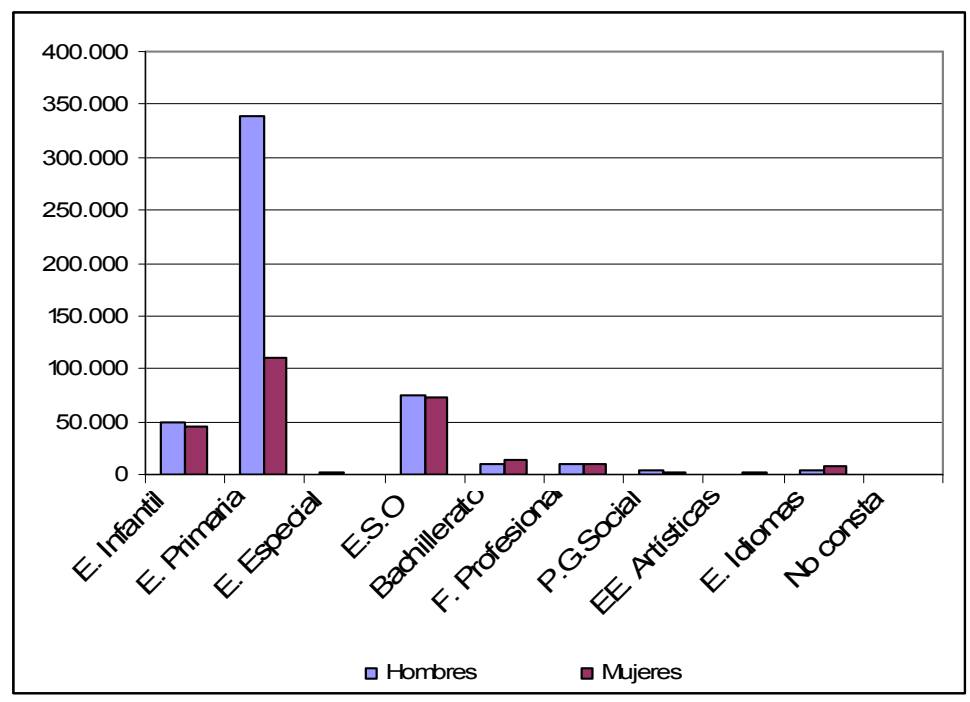

- En tercer lugar, en la distribución por nacionalidades se produce un predominio del alumnado femenino procedente del continente Americano, sobre todo de América del Sur, causando un aumento en el curso 2005-06 del 17 por ciento del alumnado femenino más que en el curso 2000-01, le siguen África y

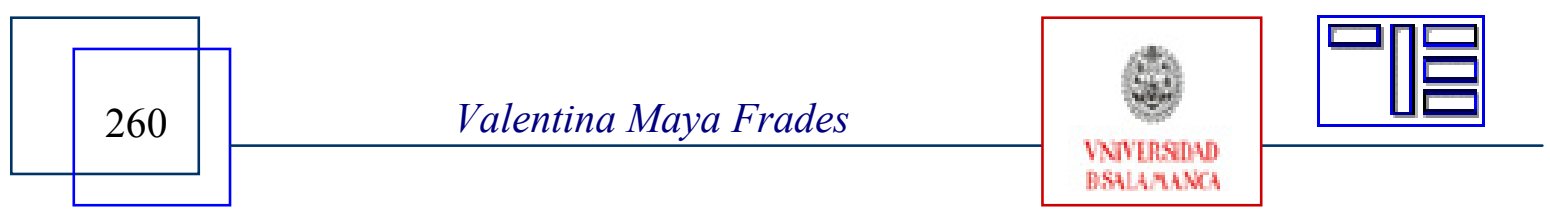


Europa, aunque tenemos que reseñar que en estos continentes se produce el fenómeno a la inversa, es decir, que en el curso 2005-06 el número de alumnas es menor (gráfico 5).

Gráfico 5: Alumnado extranjero por país de nacionalidad y sexo. Curso 2000-01

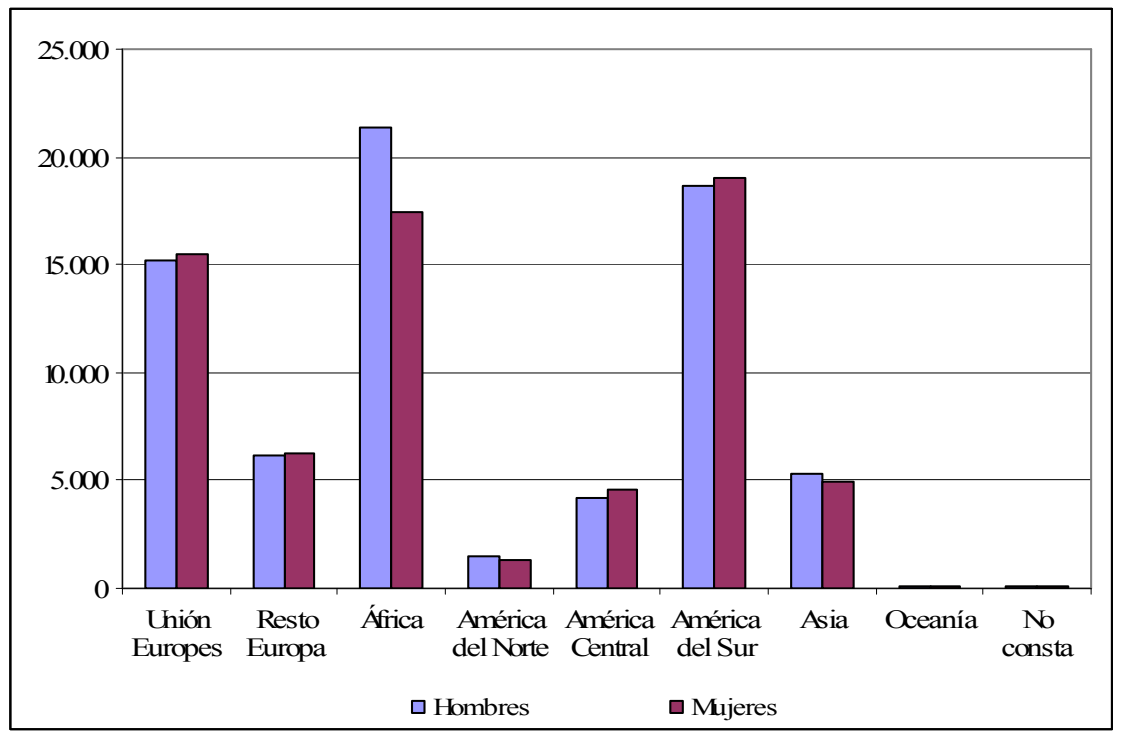

- En cuarto lugar, la proporción entre niñas y niños muestra una tendencia al equilibrio: en el curso 2000-01 las chicas eran el 48,8 por ciento y en 2005-06 (cuadro 4) habían incrementado su presencia hasta un 49,5 por ciento. Si analizamos la situación de las nacionalidades con más número de alumnas, se observa que la gran mayoría se encuentra próxima al equilibrio. En el gráfico 6 se recoge el porcentaje de alumnas en función del continente de procedencia.

Cuadro 4: Alumnado extranjero por país de nacionalidad, sexo y nivel educativo. Curso 2005-06

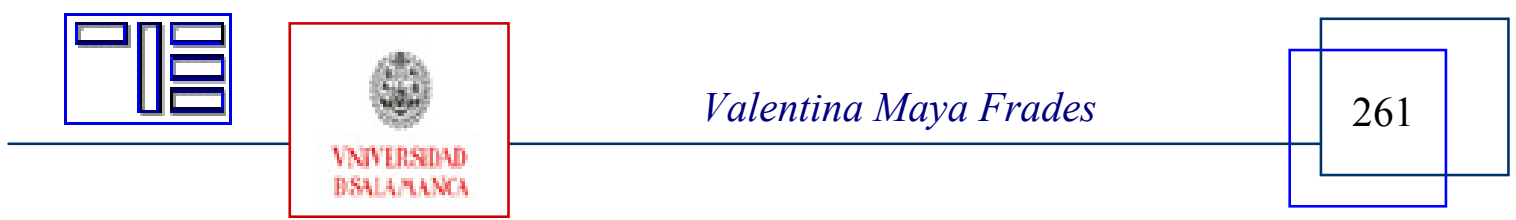


Revista Electrónica Teoría de la Educación.

Educación y Cultura en la Sociedad de la Información.

http://www.usal.es/teoriaeducacion

Vol. 9. No 2. Mayo 2008

$\begin{array}{lllllll}\text { E. } & \text { E. } & \text { E. } & \text { BACHILLE- FORMACIÓN } & \text { PROG. } & \text { EE. } & \text { E. }\end{array}$

TOTAL INFANTIL PRIMARIA ESPECIAL E.S.o. RATO PROFESIONAL GaRANTÍA ARTísticas IDIOMAS DEPORTIVAS

SOCIAL

\begin{tabular}{|c|c|c|c|c|c|c|c|c|c|c|c|c|}
\hline \multirow{3}{*}{ Total } & & & & & & \multicolumn{7}{|c|}{ SUCIAL } \\
\hline & Hombres & 268.350 & 48.373 & 339.205 & 1.123 & 74.943 & 8.870 & 8.885 & 3.777 & 907 & 3.172 & 26 \\
\hline & Mujeres & 262.604 & 45.789 & 110.568 & 740 & 72.023 & 13.066 & 10.407 & 1.329 & 1.411 & 7.271 & 0 \\
\hline Europa & Hombres & 34.707 & 6.629 & 15.033 & 77 & 9.480 & 1.448 & 867 & 126 & 183 & 856 & 8 \\
\hline (U.E.) & Mujeres & 36.039 & 6.434 & 14.554 & 40 & 9.458 & 2.022 & 983 & 57 & 384 & 2.107 & 0 \\
\hline Resto de & Hombres & 36.036 & 6.703 & 16.382 & 60 & 10.137 & 1.208 & 822 & 376 & 143 & 204 & 1 \\
\hline Europa & Mujeres & 36.630 & 6.330 & 15.228 & 54 & 10.268 & 2.311 & 1.090 & 142 & 256 & 951 & 0 \\
\hline \multirow[t]{2}{*}{ África } & Hombres & 55.925 & 13.273 & 23.601 & 337 & 13.874 & 832 & 1.960 & 1.714 & 28 & 304 & 2 \\
\hline & Mujeres & 48.031 & 11.652 & 21.245 & 243 & 11.291 & 1.198 & 1.545 & 401 & 22 & 434 & 0 \\
\hline América & Hombres & 2.817 & 528 & 1.067 & 3 & 671 & 272 & 136 & 12 & 37 & 91 & 0 \\
\hline del & Mujeres & 2.855 & 498 & 1012 & 4 & 611 & 269 & 144 & 4 & 59 & 254 & 0 \\
\hline \multicolumn{13}{|l|}{ Norte } \\
\hline América & Hombres & 9.192 & 1.172 & 3.701 & 94 & 3.169 & 344 & 371 & 226 & 26 & 89 & 0 \\
\hline Central & Mujeres & 9.946 & 1143 & 3510 & 46 & 3623 & 634 & 566 & 146 & 47 & 231 & 0 \\
\hline América & Hombres & 115.595 & 17.729 & 52.955 & 486 & 32.868 & 4.208 & 4.480 & 1.269 & 439 & 1.148 & 13 \\
\hline del Sur & Mujeres & 115.492 & 16.812 & 50.124 & 321 & 32.865 & 5949 & 5806 & 562 & 533 & 2520 & 0 \\
\hline \multirow[t]{2}{*}{ Asia } & Hombres & 13.334 & 2.099 & 5.332 & 43 & 4.586 & 501 & 235 & 54 & 48 & 434 & 2 \\
\hline & Mujeres & 12.836 & 2689 & 4697 & 25 & 3769 & 605 & 253 & 17 & 108 & 673 & 0 \\
\hline \multirow[t]{2}{*}{ Oceanía } & Hombres & 149 & 35 & 48 & 0 & 37 & 12 & 4 & 0 & 3 & 10 & 0 \\
\hline & Mujeres & 129 & 27 & 36 & 0 & 27 & 17 & 4 & 0 & 2 & 16 & 0 \\
\hline No & Hombres & 595 & 205 & 155 & 23 & 121 & 45 & 10 & 0 & 0 & 36 & 0 \\
\hline consta & Mujeres & 646 & 204 & 162 & 7 & 111 & 61 & 16 & 0 & 0 & 85 & 0 \\
\hline
\end{tabular}

Fuente: MEC. Elaboración propia

Gráfico 6: Alumnado femenino según continente

Curso 2000-01

Curso 2005-06
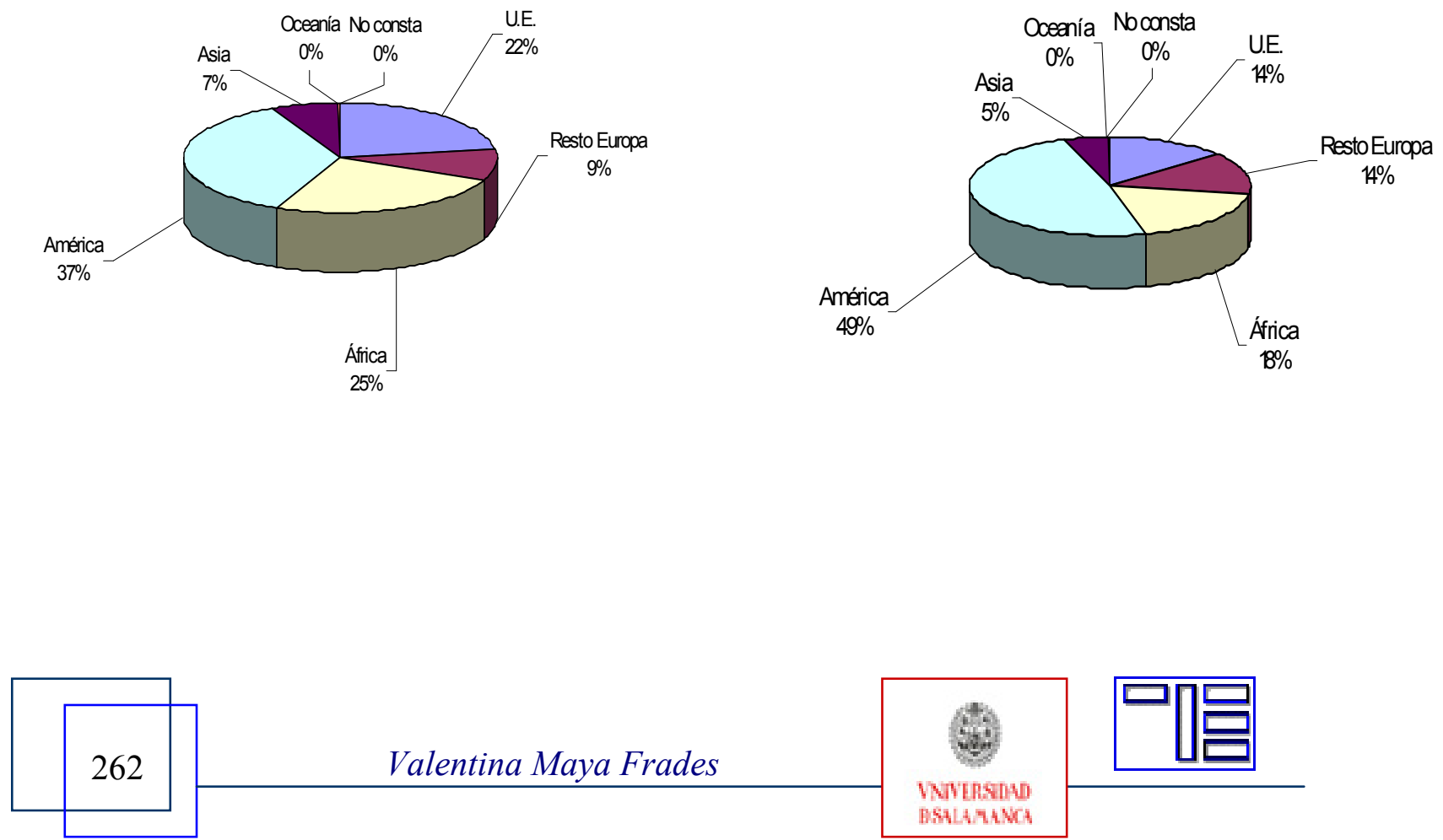


\section{5.- CONCLUSIONES.}

La población inmigrante llegada a España se caracteriza por la aceleración de su ritmo de crecimiento y la gran diversidad de países y culturas de origen. A lo largo de las páginas precedentes hemos podido comprobar que el fenómeno de la inmigración en España es un hecho reciente y por lo tanto es en la última década cuando hemos podido percibir los pros y los contras que puede acarrear este acontecimiento. También es verdad que el hecho en sí le ha reportado a España más beneficios que perjuicios, se ha visto enriquecida por otras culturas y se ha producido un choque cultural al que no estaba acostumbrada. Dentro de todo el entramado que entra a formar parte de este fenómeno, no podemos olvidar al papel que juega la educación, siendo ésta un derecho básico y como tal a través de ella se puede luchar contra toda forma de discriminación entre las personas, facilitando la integración social de todos los individuos y la igualdad de oportunidades.

Debemos educar en la pluralidad, en el respeto y en la diversidad, contribuyendo con ello a la formación de individuos capaces de integrarse social y culturalmente en la sociedad. La diversidad cultural de las sociedades significa enriquecimiento, y no una amenaza a la propia identidad cultural, por otra parte también diversa. La incorporación de otros valores culturales ha sido siempre un factor positivo para el desarrollo de los individuos y de las sociedades.

Para conseguir todo lo señalado debemos llevar a la práctica educativa una verdadera educación intercultural, capaz de acoger la diversidad, que modifique estereotipos y prejuicios, que favorezca el conocimiento de las culturas minoritarias, promoviendo actitudes, conductas y cambios sociales que eviten la discriminación y favorezcan las relaciones positivas, posibilitando el desarrollo de todas las culturas que conviven. Se necesita modificar los patrones de funcionamiento de la educación, la selección y el desarrollo de los currícula, hacia una programación intercultural en la que los intereses de todos queden representados, con una estructura curricular diferente a la dominante y una mentalidad distinta entre el profesorado, alumnado, padres y madres, administración educativa y libros de texto.

Tenemos que pensar que la escuela como agente de socializador secundario juega un papel fundamental en todo el proceso de desarrollo, pero no actúa sola, sino que hay una serie de conocimientos y actitudes que se adquieren fuera del aula escolar, sobre todo el conocimiento social: medios de comunicación (televisión, prensa, radio), cine, comics, están cargados de estereotipos y prejuicios que influyen en los estudiantes tanto o más que los aprendizajes propiamente escolares.

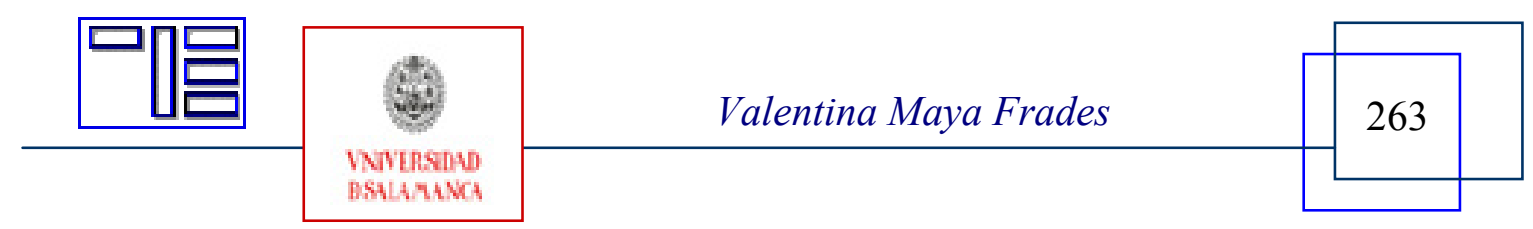




\section{6.- BIBLIOGRAFÍA.}

ARRANZ, F. (2000). Las políticas públicas a favor de las mujeres: de la teoría a la práctica. Madrid: Instituto de Investigaciones Feministas de la Universidad Complutense de Madrid.

ÁVILA RUÍZ, R. M (2005). Repensando la enseñanza del arte, desde una perspectiva multicultural. Implicaciones didácticas. En: Enseñar Ciencias Sociales en una Sociedad Multicultural. Una Mirada desde el Mediterráneo. Universidad de Almería: Servicio de Publicaciones.

BAJO BAJO, M. J. \& MAYA FRADES, V. (2007). La educación intercultural en Castilla y León. En GIRÓ MIRANDA, J. La Escuela del Siglo XXI. La Educación en un tiempo de Cambio Social Acelerado. Logroño: Universidad de la Rioja.

BERNARDO S. (2001). Mujer e Inmigración. Revista Aequalitas; 6. Retrieved from: http://www.noticias.juridicas.com

BERTOSSI, C. (2007). French and British models of integration. Public philosophies, policies and state institutions, retrieved from: http://www.ifri.org/files/Migration/CompasCB.pdf

BESALÚ, X. (2004). La formación inicial en Interculturalidad. en JORDAN SIERRA, J. A. y otros: La formación del Profesorado en Educación Intercultural. Madrid: Catarata.

BOLETÍN ESTADÍSTICO DE EXTRANJERÍA E INMIGRACIÓN, 2007, nº 14.

BOYD, M. \& GRIECO, E. (2003): Women and migration: incorporating gender into international migration theory. Migration Information Source.

BRUQUETAS, M. Y GARCÉS, B. (2007). Reflexiones sobre el fracaso del multiculturalismo y el advenimiento de las políticas asimilacionistas en Holanda", Comunicaciones del V Congreso sobre la Inmigración en España, Retrieved from http://www.adeit.uv.es/inmigracion2007/index.php

COLAS, P. y JIMÉNEZ, M. R. (2004). El Discurso de Género en los Centros Educativos. Revista de Ciencias de la Educación, 197, pp. 69-93.

COLECTIVO IOE (2003). La escolarización de hijas de familias inmigrantes.Madrid: Instituto de la Mujer.

COLECTIVO IOÉ (2005). Inmigrantes extranjeros en España: ¿reconfigurando la sociedad?. Panorama Social, 1, pp. 32-47.

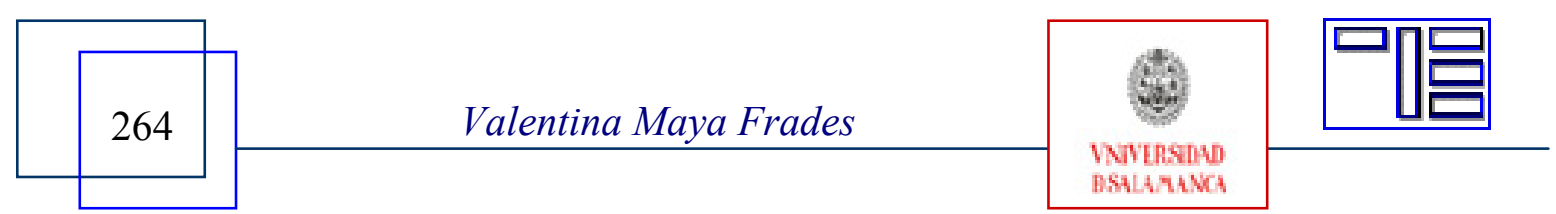


DEPARTAMENTO CONFEDERAL DE LA MUJER DE UGT (2000). Mujeres Inmigrantes. Comisión Ejecutiva Confederal de UGT.

DÍAZ-AGUADO, M . J. \& BARAJA, A. (1993).Interacción educativa y desventaja sociocultural. Un modelo de intervención para favorecer la adaptación escolar en contextos Inter.étnicos. Madrid: CIDE.

GARCÍA CARRASCO, J., GROS, B. \& AYUSTE, A (2002). Sociedad-Red educación e identidad, en E. GERVILLA (Coord.) Globalización, Inmigración y Educación. Granada: Diputación Provincial de Granada, pp. 25-91.

GIL, F. J. (2005). Adversus barbaros. Retrieved from: http://www.disc.ua.es/ gil/adversus.pdf

GREGORIO C. (1995). El proceso de integración social de las mujeres inmigrantes, en DÍAZ-AGUADO, M. J, et al. Las mujeres inmigrantes y su integración social. Madrid: Instituto de la Mujer, Ministerio de Asuntos Sociales, pp. 47-69.

INSTITUTO NACIONAL DE ESTADÍSTICA. http://www.ine.es

JORDAN, J. A. (1994). La escuela multicultural. Un reto para el profesorado. Barcelona: Paidós.

LEY ORGÁNICA DE ORDENACIÓN GENERAL DEL SISTEMA EDUCATIVO (Ley Orgánica 1/1990, de 3 de Octubre).

MARTÍN DIAZ, E. (2004): Inmigración, multiculturalidad y género. Sevilla: Instituto Andaluz de la Mujer.

MARTÍNEZ TEN, L. \& TUTS, M. (2003). Derechos humanos, mujer e inmigración: Hacia una educación intercultural en el aula. Retrieved from: http://www.nodo50.org/ddhhmujeres/dossier/web/indice.htm

MEC (2004). Una educación de calidad para todos y entre todos. Propuestas para el debate. Madrid

MERINO, S. (2005). La Escuela y la Diversidad. En: Enseñar Ciencias Sociales en una Sociedad Multicultural. Una Mirada desde el Mediterráneo. Universidad de Almería: Servicio de Publicaciones.

PEREDA, C. (Colectivo Ioé9 (2007). Dos claves para comprender las migraciones internacionales. El caso de España. Colloque Internacional Migrants de la Cité a la Citoyenneté: Etat des Linux des recherches européennes. Luxemburgo.

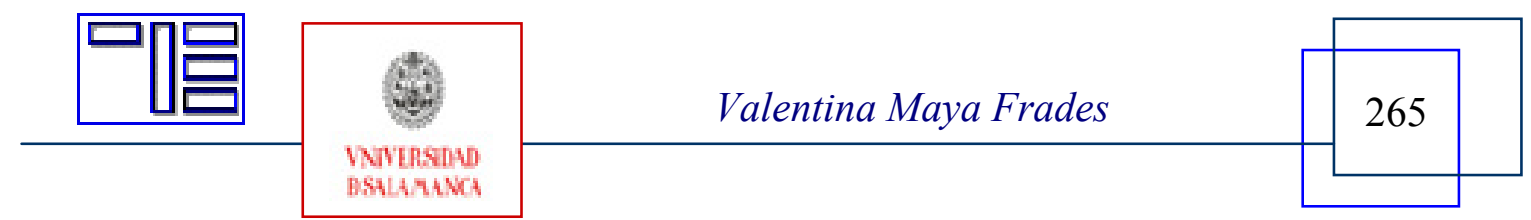


Revista Electrónica Teoría de la Educación.

Educación y Cultura en la Sociedad de la Información.

http://www.usal.es/teoriaeducacion

Vol. 9. No 2. Mayo 2008

PNUD (2004). Informe sobre Desarrollo Humano 2004. Libertad cultural en el mundo diverso de hoy, Madrid, Ediciones Mundi-Prensa.

RUÍZ EXPOSITO, M. D. (2005). Interculturalidad en nuestras aulas. En: Enseñar Ciencias Sociales en una Sociedad Multicultural. Una Mirada desde el Mediterráneo. Universidad de Almería: Servicio de Publicaciones.

SARTORI G. (2003). La sociedad multiétnica. Pluralismo, multiculturalismo, extranjeros e islámicos. Madrid: Taurus.

SORIANO AYALA, E. (2005). La interculturalidad como factor de calidad educativa. Madrid: La Muralla.

SORIANO AYALA, E. (2006). La mujer en la perspectiva intercultural. Madrid: La Muralla.

SUBIRATS MARTORI, M. (1994). Conquistar la igualdad: la coeducación hoy. Revista Iberoamericana de educación, 6, pp. 49-78.

TERRÉL LALANA, E. (2008). Una esperanza vulnerable: las mujeres de la inmigración, en MAYA FRADES, V. Mujeres rurales. Estudios multidisciplinares de género, Salamanca: Ediciones Universidad de Salamanca, 129, pp. 363-376.

VV.AA. (2006). De la España que emigra a la España que acoge. Madrid: Fundación Francisco Largo Caballero y Obra Social de Caja Duero.

Otras fuentes electrónicas consultadas:

http://www.un.org/depts/dhl/spanish/events/migrants/index.html

http://www.stecyl.es/informes/inmigracion/inmigracion.htm

http://www.acoge.org/documentos.htm

http://extranjeros.mtas.es

www.aulaintercultural.org

\section{Notas:}

\footnotetext{
${ }^{1}$ El 10 de diciembre de 1948, la Asamblea General de las Naciones Unidas aprobó y proclamó la Declaración Universal de Derechos Humanos. En el artículo 13 dice que: 1 . Toda persona tiene derecho a circular libremente y a elegir su residencia en el territorio de un Estado. 2. Toda persona tiene derecho a salir de cualquier país, incluso del propio, y a regresar a su país.
}

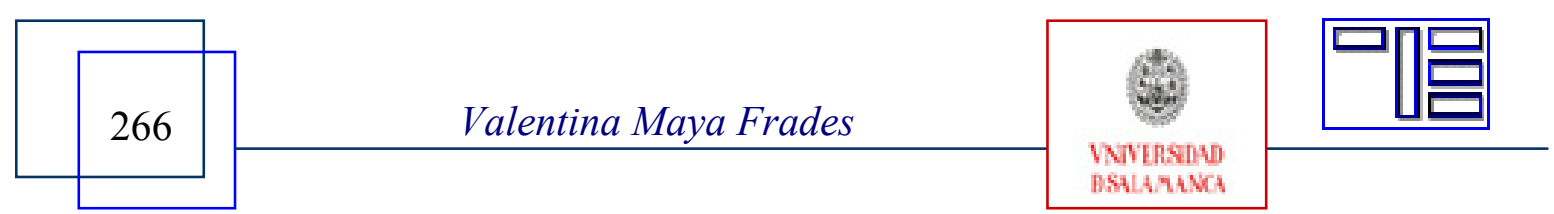


${ }^{2}$ La Asamblea General, teniendo en cuenta que existe un importante número de inmigrantes en el mundo, y que ese número continúa incrementándose, proclamó el 4 de diciembre de 2000 día Internacional del Migrante (resolución 45/158). El día 18 de diciembre se conmemora el Día Internacional de las personas migrantes, es un momento idóneo para trabajar con los alumnos/as este tema.

Los movimientos migratorios han crecido mucho en los últimos años. Actualmente, alrededor de 150 millones de personas viven y trabajan fuera de sus países de origen. España, es uno de ellos de donde no hace mucho tiempo salían migrantes hacia Europa del Norte y América, hoy se ha convertido en un país receptor para un gran número de personas migrantes.

${ }^{3}$ La breve historia del Estado Español como receptor de inmigrantes, radica en la intensidad que ha alcanzado el fenómeno en un breve espacio de tiempo. Países europeos con mayor tradición como receptores de inmigración han dispuesto de décadas hasta alcanzar porcentajes de población extranjera similares a los que España ha alcanzado tan sólo en siete u ocho años.

${ }^{4}$ En un estudio sobre género y migración en Europa, se llega a la conclusión de que la mayoría de los estudios parecen imparciales en materia de género, aunque se utilizan modelos de migración basados en las experiencias de hombres. Las mujeres, en los casos en que se reconoce su presencia, suelen ser incluidas en la categoría de familiares a cargo, que migran por razones de reunificación de la familia, y no se tiene en cuenta sus aportaciones a la economía y la sociedad de los países de destino (Kofman y otros 2000, 3).

${ }^{5}$ Según los datos del último Padrón Municipal (realizado el 1 de enero de 2007), publicados por el Instituto Nacional de Estadística (INE).

${ }^{6}$ El reagrupamiento familiar de los inmigrantes como derecho es un tema reciente en la legislación española. Es necesario que en todos los países se introduzcan en sus legislaciones normas para controlar las distintas situaciones en las que pueden encontrarse los extranjeros.

Se reconocerá el reagrupamiento familiar como un derecho que deriva del ámbito constitucional, del derecho a formar una familia, a la intimidad familiar, reconocidos en el propio texto constitucional, arts. 39 y 18, así como, la vía a través de la que se puede lograr el libre desarrollo de la personalidad individual, art. $10.1^{\circ}$ de la Carta Magna. Se considera que el reagrupamiento favorece el arraigo del extranjero en el país de acogida.

${ }^{7}$ El multiculturalismo ha sido también la opción escogida por el Programa de Naciones Unidas para el Desarrollo en su informe sobre Desarrollo Humano del año 2004 (PNUD, 2004). El enfoque desde el que este informe aborda la construcción del multiculturalismo y el avance de la libertad cultural, puede tomarse como un referente más para la elaboración de políticas públicas encaminadas a la integración con los inmigrantes. Naciones Unidas lanza así, a través de este informe, una apuesta decidida para el avance de un multiculturalismo ligado a la defensa de los Derechos Humanos, el Estado de Derecho, la igualdad de género, la diversidad y la tolerancia.

8 "La libertad cultural exige defender las prácticas tradicionales, de modo que podría haber una disyuntiva entre reconocer la diversidad cultural y otras prioridades del desarrollo humano, como el progreso en el desarrollo, la democracia y los derechos humanos". (PNUD, 2004: 4)

${ }^{9}$ Los datos del Anuario 2006 se refieren exclusivamente a las personas que disponían de tarjeta de autorización de estancia por estudios vigente el 31 de diciembre de 2006.

${ }^{10}$ Se trata de Educación Infantil, Primaria, Especial, Bachillerato, Formación Profesional, Garantía Social, Enseñanza Artísticas, Idiomas y Enseñanzas Deportivas.

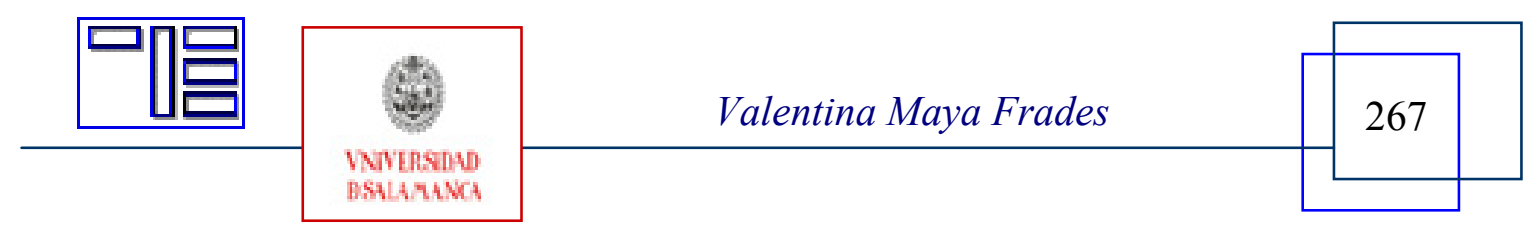


Revista Electrónica Teoría de la Educación.

Educación y Cultura en la Sociedad de la Información.

Para citar este artículo puede utilizar la siguiente referencia:

MAYA FRADES, Valentina (2008). Mujer e inmigración: educación en las aulas. En APARICIO, Pablo (Coord.) Desde la diversidad hacia la desigualdad: ¿destino inexorable de la globalización? [monográfico en línea]. Revista Electrónica Teoría de la Educación: Educación y Cultura en la Sociedad de la Información. Vol. 9, n². Universidad de Salamanca. [Fecha de consulta: dd/mm/aaaa]. $<\mathrm{http}: / /$ www.usal.es/ teoriaeducacion/rev_numero_09_02/n9_02_maya.pdf $>$ ISSN 1138-9737 